\title{
Intervenciones no voluntarias en materia de salud en el Derecho Español
}

Involuntary interventions in health in Spanish Law

\section{Ángela Ruiz Sáenz}

Licenciada en Derecho. Asesora Jurídica del Servicio de Asesoramiento Jurídico de la Consejería de Sanidad y Servicios Sociales del Gobierno de Cantabria, España.

\section{Gustavo Merino Gómez}

Licenciado en Derecho. Asesor Jurídico del Servicio de Asesoramiento Jurídico de la Consejería de Sanidad y Servicios Sociales del Gobierno de Cantabria, España.

Resumen: El paciente se configura como el eje básico de las relaciones clínicoasistenciales requiriendo toda actuación en el ámbito de su salud del consentimiento libre y voluntario del mismo. En este sentido, tiene derecho a negarse al tratamiento, excepto en los casos determinados en la ley. El presente trabajo tiene por objeto el estudio de algunas situaciones en las que el legislador ha previsto la posibilidad de adoptar medidas dirigidas a preservar la salud del paciente sin contar con el consentimiento del mismo: las medidas relativas al internamiento no voluntario por razón de trastorno psiquiátrico y las intervenciones obligatorias por riesgo de transmisión de enfermedades contagiosas, en concreto, la hospitalización forzosa y la vacunación.

Palabras claves: Autonomía del paciente; consentimiento informado; derechos fundamentales; hospitalización forzosa.

Resumo: O paciente é o eixo básico das relações clínico-assistenciais, sendo requerido seu consentimento livre e voluntário em todas as intervenções no âmbito de sua saúde. Nesse sentido, tem direito a negar-se a receber tratamento, exceto nos casos determinados pela lei. $O$ artigo analisa algumas situações nas quais o legislador previu a possibilidade da adoção de medidas para preservar a saúde do paciente sem contar com o seu consentimento: aquelas relativas à internação involuntária em razão de transtorno psiquiátrico e as intervenções obrigatórias por risco de transmissão de doenças contagiosas; concretamente, a hospitalização involuntária e a vacinação.

Palavras chave: Autonomia do paciente; consentimento informado; direitos fundamentais; hospitalização involuntária. 


\begin{abstract}
The patient is the key feature of clinical-care relationships. Therefore, any healthcare action needs his voluntary and informed consent. In this regard, the patient has the right to refuse treatment, except in the cases determined by Law. The present work aims to study some situations where the law provides the possibility of taking measures to preserve the health of the patient without his consent: measures relating to psychiatric involuntary internment and mandated interventions for risk of transmission of infectious diseases, in particular, forced hospitalization and vaccination.
\end{abstract}

Keywords: Patient autonomy; informed consent; fundamental rights; involuntary hospitalization.

\title{
1 Introducción
}

El paciente se configura como el eje básico de las relaciones clínicoasistenciales requiriendo toda actuación en el ámbito de su salud el consentimiento libre y voluntario del mismo. Si durante siglos la actividad del profesional sanitario se rigió por el denominado principio de beneficencia, en el que el médico se consideraba legitimado para buscar el mejor interés del enfermo pero sin tener en cuenta su opinión, esto es, actuar de acuerdo con la voluntad del enfermo, pero también sin su voluntad o incluso contra ella (todo para el paciente pero sin el paciente), actualmente no cabe duda de la consagración normativa del principio de autonomía del paciente, elemento esencial de la relación médico paciente, que implica un poder de autodeterminación que debe ser respetado y que proscribe la imposición de tratamientos coactivos por bienintencionados que sean (Cayón de las Cuevas et. al., $2011)^{1}$.

El paciente se convierte así en el único titular del derecho a decidir sobre su salud. En este sentido, el artículo 2 de la Ley 41/2002, de 14 de noviembre, básica reguladora de la autonomía del paciente y de derechos y obligaciones en materia de información y documentación clínica dispone, en su apartado 2, que toda actuación en el ámbito de la salud de un paciente necesita el consentimiento libre y voluntario del afectado, una vez que, recibida la información disponible sobre la misma, haya valorado las opciones propias del caso, y reconoce, en su apartado 4, el derecho de todo paciente o usuario a negarse al tratamiento, excepto en los casos determinados en la Ley.

\footnotetext{
${ }^{1}$ El trabajo aborda precisamente los mecanismos extrajudiciales para resolver los conflictos generados como consecuencia de la consagración normativa del principio autonomista y de la coparticipación del usuario en el proceso de toma de decisiones clínicas.
} 
Al hilo de lo anterior, el presente trabajo tiene por objeto el estudio de algunas situaciones en las que el legislador ha previsto la posibilidad de adoptar medidas dirigidas a preservar la salud del paciente sin contar con el consentimiento del mismo, concretamente, por un lado, las medidas relativas al internamiento no voluntario por razón de trastorno psíquico y por otro, las intervenciones obligatorias por riesgo de transmisión de enfermedades contagiosas, y en concreto, la hospitalización forzosa y la vacunación.

\section{Internamiento no voluntario por razón de trastorno psíquico ${ }^{2}$}

\subsection{Régimen jurídico.}

El artículo 43 de la Constitución Española (en lo sucesivo CE) reconoce el derecho a la protección de la salud y atribuye a los poderes públicos la competencia para organizar y tutelar la salud pública a través de medidas preventivas y de las prestaciones y servicios necesarios encomendando a la ley el desarrollo normativo de los derechos y deberes de todos al respecto.

Paralelamente, el artículo 17 CE reconoce a toda persona el derecho a la libertad y a la seguridad, indicando que nadie puede ser privado de su libertad, sino con la observancia de lo establecido en ese artículo y en los casos y en la forma previstos en la Ley ${ }^{3}$.

Por su parte, el artículo 49 CE señala que los poderes públicos realizarán una política de previsión, tratamiento, rehabilitación e integración de los disminuidos físicos, sensoriales y psíquicos, a los que prestarán la atención especializada que requieran y los ampararán especialmente para el disfrute de los derechos que este título otorga a todos los ciudadanos.

La regulación legal de un derecho fundamental, como es la libertad individual referida a un sujeto que sufre un trastorno psíquico, consagrado a nivel constitucional en el artículo $17 \mathrm{CE}$, ha sido desarrollada, únicamente en su vertiente procesal, mediante la Ley $1 / 2000$, de 7 de enero, de Enjuiciamiento Civil (en adelante LEC) que

\footnotetext{
2 Sobre esta cuestión pueden consultarse los siguientes trabajos que abordan la materia de una forma más ampliada: Delgado Bueno (2011); Barrios Flores (2003); Barrios Flores (2005); Barrios Flores (2012); García García (2000); Martín Vázquez (2008); Merino Gómez (2011a); y Merino Gómez (2011b).

${ }^{3}$ Junto a estos preceptos no debe olvidarse lo señalado en el artículo 10.2 CE que determina que las normas relativas a los derechos fundamentales y a las libertades que la Constitución establece deberán interpretarse de conformidad con la Declaración Universal de Derechos Humanos y los Tratados y acuerdos internacionales sobre las mismas materias ratificados por España.
} 
indica que el internamiento de una persona que no esté en condiciones de decidirlo por sí, aunque esté sometida a la patria potestad o a tutela, requerirá autorización judicial, que será recabada del tribunal del lugar donde resida la persona afectada por el internamiento.

Transcurridos diez años desde la aprobación de la LEC $^{4}$ el Tribunal Constitucional, en las Sentencias núm. 131/2010, de 2 de diciembre de 2010, que resolvió la cuestión de inconstitucionalidad 4511-1999, y núm. 132/2010, de 2 de diciembre de 2010, dictada en cuestión de inconstitucionalidad 4542-2001, se han pronunciado con rotundidad acerca del régimen jurídico existente en nuestro ordenamiento jurídico en materia de internamiento no voluntario por razón de trastorno psíquico, poniendo de manifiesto el incorrecto desarrollo legal realizado de un derecho fundamental como es la libertad individual de los pacientes de algún trastorno o enfermedad mental.

Cabe destacar que el legislador estatal únicamente invocó como competencia habilitante para dictar el referido precepto la relativa a la legislación procesal incluida en el artículo 149.1.6 CE, obviando cualquier dimensión sustantiva que afecte a un derecho fundamental. Es por ello que, ni siquiera incluyó en la Disposición Adicional Primera de la LEC referencia al artículo 149.1.1 CE que le atribuye competencia exclusiva en la regulación de las condiciones básicas que garanticen la igualdad de todos los españoles en el ejercicio de los derechos y en el cumplimiento de los deberes constitucionales.

Una de las garantías que los artículos 53 y 81 de la CE dispensan a la libertad individual, como derecho incluido dentro del denominado "núcleo duro" de los derechos fundamentales, es la necesidad de que el desarrollo legal se realice mediante ley orgánica. Sin embargo, el internamiento no voluntario, cuando se ordena como consecuencia del padecimiento de un trastorno psíquico del sujeto, no ha merecido el mismo tratamiento que otras limitaciones de la libertad individual, como las derivadas de la comisión de un delito o falta ${ }^{5}$ o la regulación de las medidas excepcionales en materia de salud pública $^{6}$, sino que, a diferencia de aquellas, ha sido regulada mediante una ley ordinaria.

\footnotetext{
${ }^{4}$ Y diez años después de la derogación del artículo 211 del Código Civil.

5 Ley Orgánica 10/1995, de 23 de noviembre, del Código Penal y Ley Orgánica 6/1984, de 24 de mayo, Reguladora del Procedimiento Habeas Corpus.

${ }^{6}$ Ley Orgánica 3/1986, de 14 de abril, de medidas especiales en materia de salud pública.
} 
Así, la Sentencia núm. 132/2010, de 2 de diciembre de 2010, dictada con ocasión de la cuestión de inconstitucionalidad 4542-2001, declara inconstitucional pero no nulo ${ }^{7}$, el inciso «el internamiento, por razón de trastorno psíquico, de una persona que no esté en condiciones de decidirlo por sí, aunque esté sometida a la patria potestad o a tutela, requerirá autorización judicial» del artículo 763.1, párrafo primero, de la LEC. La misma tacha de inconstitucionalidad se proyecta sobre el inciso «la autorización será previa a dicho internamiento, salvo que razones de urgencia hicieren necesaria la inmediata adopción de la medida» del párrafo tercero del mismo artículo. ${ }^{8}$

Por su parte, la Sentencia núm. 131/2010, de 2 de diciembre de 2010, que resolvió la cuestión de inconstitucionalidad 4511-1999, declara en primer lugar, inconstitucional y nula la disposición final vigésima tercera de la Ley Orgánica 1/1996, de 15 de enero, de protección jurídica del menor. Por otra parte, califica inconstitucional, pero no nulo ${ }^{9}$, el párrafo primero del artículo 211 del Código Civil ${ }^{10}$,

\footnotetext{
${ }^{7}$ En el presente caso el Tribunal no sanciona el precepto con la nulidad radical argumentando que " $A$ esta declaración de inconstitucionalidad no debe anudarse en este caso la declaración de nulidad pues esta última crearía un vacio en el Ordenamiento jurídico no deseable, máxime no habiéndose cuestionado su contenido material. [...] Estamos, por consiguiente, en presencia de una vulneración de la Constitución que sólo el legislador puede remediar; razón por la que resulta obligado instar al mismo para que, a la mayor brevedad posible, proceda a regular la medida de internamiento no voluntario por razón de trastorno psíquico mediante ley orgánica." Ello parece contravenir lo indicado en el artículo 39.1 de la Ley Orgánica 2/1979, de 3 de octubre, del Tribunal Constitucional que señala "Cuando la sentencia declare la inconstitucionalidad, declarará igualmente la nulidad de los preceptos impugnados, así como, en su caso, la de aquellos otros de la misma Ley, disposición o acto con fuerza de Ley a los que deba extenderse por conexión o consecuencia. Sin embargo existen antecedentes en los que el Tribunal ha declarado en diversas ocasiones, no siempre es necesaria la vinculación entre inconstitucionalidad y nulidad (SSTC 45/1989, de 20 de febrero, FJ 11; 138/2005, de 26 de mayo, FJ 6; 273/2005, de 27 de octubre, FJ 9; 236/2007, de 7 de noviembre, FJ 17; y 120/2010, de 24 de noviembre, FJ 6).

${ }^{8}$ Debe entenderse que el Tribunal Constitucional se refiere al párrafo segundo del artículo 763.1 LEC y no al tercero tal y como cita la sentencia.

${ }^{9}$ Nada hubiera impedido al Tribunal Constitucional declarar nulo e inconstitucional el citado precepto, teniendo en cuenta que fue derogado hace más de once años y que su derogación no crearía en el ordenamiento jurídico vacío legal alguno como sí sucede en el caso de la anulación del artículo 763 LEC.

${ }^{10}$ La Sentencia del Tribunal Constitucional núm. 129/1999, de 1 de Julio de 1999 referida al segundo párrafo del artículo 211 del Código Civil, no sancionó con la inconstitucionalidad el citado precepto, por entender que el mismo no era la "norma que en nuestro Derecho permite el internamiento de personas que padezcan trastornos psíquicos. Esa posibilidad se establece y disciplina en el párrafo primero del mismo precepto, que habilita al Juez para acordar una privación de libertad en el concreto supuesto ahí contemplado. El párrafo segundo, aquí en cuestión, regula el proceder del Juez previamente habilitado para acordar el internamiento; disciplina, por tanto, el procedimiento a cuyo través ha de conformarse la decisión judicial, pero ésta, en tanto que determinante de uno de los casos de privación de libertad referidos en el artículo 17.1 de la Constitución, trae causa de la habilitación contenida en el párrafo precedente”. De forma indirecta el Alto Tribunal entendía en 1999 que la antigua regulación del párrafo primero del artículo 211 del Código Civil era inconstitucional ya que suponía el desarrollo "de la garantía de la libertad personal establecida en el artículo 17.1 de la Constitución alcanza, desde luego, a quienes son objeto de la decisión judicial de internamiento a que se refiere el artículo 211 C.C. Es, en efecto, doctrina de este Tribunal, que dentro de los casos y formas mencionados en el articulo 17.1 «ha de considerarse incluida [...] la (detención regular... de un enajenado), a la que se refiere el artículo 5.1 del Convenio Europeo de Derechos Humanos» (STC 104/1990. En tanto que constitutiva de una privación de libertad, es obvio que la decisión de internamiento sólo puede ser acordada judicialmente y que, en lo que aqui
} 
en la redacción dada por la disposición final duodécima de la Ley Orgánica 1/1996, de 15 de enero, de protección jurídica del menor.

\subsection{Presupuestos del internamiento según la doctrina constitucional.}

Tal y como ha señalado el Tribunal Constitucional en su Sentencia 104/1990, de 4 de junio, "según el artículo 17.1 C.E. nadie puede ser privado de su libertad sino en los casos y en las formas previstos en la Ley". Dentro de esos casos y formas ha de considerarse incluida desde luego la «detención regular ... de un enajenado», a la que se refiere el artículo 5.1 del Convenio Europeo de Derechos Humanos ${ }^{11}$. La «regularidad» de esa detención depende, a su vez, de la existencia de una decisión judicial que autorice ese internamiento, cuando la situación de salud mental del afectado lo justifique.

Recientemente se ha producido el primer pronunciamiento del Tribunal Constitucional en recurso de amparo núm. 5070-2009 en esta materia. Así en Sentencia núm. 141/2012, de 2 de julio de 2012, en la que el Alto Tribunal indica que:

“a) Se configura como presupuesto objetivo de la medida la existencia en la persona de un trastorno psíquico, al que viene a sumarse la circunstancia de la "urgencia" o necesidad inmediata de la intervención médica para su protección. El significado de lo que ha de entenderse por trastorno psíquico, transitorio o permanente, en línea con lo dispuesto en instrumentos internacionales, remite a los conocimientos propios de la ciencia médica; sin que en ningún caso puedan considerarse como expresión de trastorno o enfermedad mental la discrepancia del afectado con los valores sociales, culturales, políticos o religiosos imperantes en la comunidad.

importa, el precepto que la hace posible sólo puede ser una Ley Orgánica, pues, dada su condición de norma que fija uno de los casos en que una persona puede ser privada de libertad, concurre al desarrollo del derecho fundamental garantizado en el artículo 17.1 (STC 140/1986)."

${ }^{11}$ El Convenio Europeo para la Protección de los Derechos Humanos y Libertades Fundamentales, Derecho a la Libertad y a la Seguridad garantiza, en su artículo 5.1.e), el derecho a que nadie pueda ser privado de su libertad salvo, si se trata del internamiento, conforme a derecho, entre otros, de una persona susceptible de propagar una enfermedad contagiosa, de un enajenado o de un alcohólico. 
b) La procedencia de la medida y su completa duración, deben satisfacer en cada caso concreto los requisitos de necesidad y proporcionalidad. "

Continúa el Tribunal señalando en la Sentencia núm. 141/2002 que debe atenderse a cuatro exigencias básicas derivadas del respeto al derecho fundamental a la libertad personal (art. $17 \mathrm{CE}$ ), para considerar válido el internamiento cuales son:

“a) Existencia de un informe médico que acredite el trastorno psíquico justificante del internamiento inmediato: si bien el responsable del centro médico está facultado para tomar ab initio la decisión de internar a la persona, es evidente que esto se condiciona al hecho de que consten acreditadas en ese momento y tras su reconocimiento, la necesidad y proporcionalidad de la medida, de la que ha de informarse al interesado hasta dónde le sea comprensible, debiendo quedar plasmado por escrito el juicio médico para su posterior control por la autoridad judicial

b) Información al afectado o su representante acerca del internamiento y sus causas: resulta evidente que nadie puede ser privado de libertad sin conocer los motivos que lo determinan, como proclama el art. 17.2 CE para la detención.

c) Obligación del centro de comunicar al juez competente el internamiento y los motivos que lo justificaron, en el plazo de 24 horas: la imposición de un límite temporal ha de venir impuesto por la norma legal de desarrollo, en este caso el ya citado art. 763 $L E C$, donde se señala que "el responsable del centro en que se hubiere producido el internamiento deberá dar cuenta de éste al tribunal competente lo antes posible $y$, en todo caso, dentro del plazo de veinticuatro horas, a los efectos de que proceda a la preceptiva ratificación de dicha medida". Plazo que el legislador actual o futuro no podría elevar en ningún caso más allá de las 72 horas, al resultar vinculante en este ámbito privativo de libertad la limitación que fija el art. 17.2 CE para las detenciones extrajudiciales, (...) 
d) Control posterior sobre el centro: desde que tiene lugar la comunicación antedicha ha de considerarse que la persona pasa a efectos legales a disposición del órgano judicial, sin que ello exija su traslado a presencia física del juez, como hemos tenido ocasión de precisar en el ámbito de las detenciones judiciales (SSTC 21/1997, de 10 de febrero, FJ 4; 180/2011, de 21 de noviembre, FJ 5). “

Nada señala el artículo 763 LEC en relación con las personas legitimadas para acudir al órgano jurisdiccional con el fin de que autorice el internamiento del aquejado por el trastorno psíquico. Por ello debe entenderse que analógicamente resulta aplicable el artículo 757 LEC que prevé los sujetos legitimados para promover los procesos de incapacitación y de declaración de prodigalidad, a excepción de la persona cuyo internamiento se solicita, que precisamente por padecer un trastorno se encuentra privado de su capacidad de autogobierno.

Así, pues, de conformidad con el artículo 757 LEC, están legitimados el cónyuge o quien se encuentre en una situación de hecho asimilable, descendientes, ascendientes, los hermanos de la persona cuyo internamiento se pretenda y, en el supuesto internar a un incapaz en un establecimiento de salud mental o de educación o formación especial, estará legitimado su tutor, según lo señalado en el artículo 271 del Código Civil.

La legitimación en el caso del internamiento no urgente de los menores de edad no emancipados sometidos a patria potestad o tutela presenta una serie de especialidades con respecto al régimen general. En primer lugar, deben entenderse legitimados para solicitar su internamiento no todos los previstos en el artículo 757 LEC, sino únicamente las personas que ejerzan la patria potestad o tutela ${ }^{12}$, sus hermanos mayores de edad y el Ministerio Fiscal.

En segundo lugar y en considerando que, en el caso de los menores, las personas que puede prestar su consentimiento para el tratamiento, es decir, aquellas que ostentan la patria potestad, no coincide el paciente que va a ser internado, debe analizarse si cabría la posibilidad de otorgar el consentimiento por representación en los términos del artículo 9.3 de la de la Ley 41/2002, de 14 de noviembre, básica

\footnotetext{
${ }^{12}$ No debe considerarse equivalente al concepto de ascendiente previsto en el 757 LEC, toda vez que un ascendiente puede haber sido privado de la patria potestad.
} 
reguladora de la autonomía del paciente y de derechos y obligaciones en materia de información y documentación clínica.

La dicción literal del artículo 763 LEC se refiere expresamente a la necesidad de recabar autorización judicial para el internamiento de una persona, "aunque esté sometida a la patria potestad o a tutela" por ello debe concluirse que no cabría el "ingreso voluntario" del menor, ni siquiera cuando se cuente con el consentimiento de quien ejerza la patria potestad o tutela sino que, en todo caso, será preceptiva la autorización judicial.

En los supuestos de internamiento urgente, debe entenderse que, además de los anteriores, estará legitimado para recabar la ratificación judicial de la medida de internamiento el responsable del centro en que se hubiere producido el mismo.

\section{Intervenciones obligatorias en materia de salud pública ${ }^{13}$}

\subsection{Régimen jurídico}

La atención a los problemas de salud colectiva ha tenido tradicionalmente un tratamiento diferenciado de la atención a los problemas de salud individual.

La CE reconoce el derecho a la protección de la salud tanto en su vertiente individual, es decir el derecho de cada persona a la protección de su salud, como en su vertiente colectiva, como un derecho de la colectividad ${ }^{14}$. En este sentido, tal y como se ha señalado previamente, la CE reconoce en su artículo 43, apartado 1, el derecho a la protección de la salud, señalando, en su apartado 2, la competencia de los poderes públicos para la organización y tutela de la salud pública a través de las medidas preventivas y de las prestaciones y servicios necesarios.

Ante la necesidad de renovación y la insuficiente legislación existente en materia de salud pública, una legislación obsoleta sobre una materia relegada a un segundo plano a partir de la segunda mitad del siglo XX como consecuencia de una

\footnotetext{
${ }^{13}$ Véase Ruiz Sáenz (2011).

${ }^{14}$ En relación con el derecho a la protección de la salud reconocido en el artículo 43 de la CE, Fernández Montalvo (2010) alude a la distinción tradicional por la doctrina de un aspecto negativo y un aspecto positivo del derecho a la salud. En este sentido, el aspecto negativo se traduciría en un límite frente a determinadas injerencias del poder público referidas no solo a la salud sino también a la vida, la integridad física y moral. En un sentido positivo, el derecho a la salud conlleva un derecho a exigir de los poderes públicos actuaciones y prestaciones en un doble sentido: a) la adopción de aquellas medidas tendentes a controlar y asegurar la protección de la salud en situaciones de riesgo y a preservar y mejorar el ambiente sanitario general y b) el derecho a la asistencia sanitaria que comprende las prestaciones médicas o sanitarias encaminadas a la preservación o al restablecimiento de la salud.
} 
mayor atención a los problemas de la salud individual, surge la Ley 33/2011, de 4 de octubre, General de Salud Pública (en adelante LGSP).

La LGSP se configura como una ley de carácter preferentemente preventivo, no sólo proteccionista, tanto en el ámbito de la salud individual como en el ámbito de la salud colectiva, haciendo especial hincapié en la participación activa de la sociedad en materia de salud pública. En este sentido, la citada ley señala en su preámbulo que "la excelente respuesta que hemos dado al requerimiento constitucional de protección de la salud desde la vertiente del cuidado de las personas enfermas debe ahora complementarse con la vertiente preventiva y de protección y promoción de la salud".

La LGSP configura la salud pública, más allá del "conjunto de iniciativas organizadas por las Administraciones Públicas para preservar, proteger y promover la salud de la población", a que se refiere el artículo 11.1 de la Ley 16/2003, de 28 de mayo, de cohesión y calidad del Sistema Nacional de Salud, como el "conjunto de actividades organizadas por las Administraciones Públicas, con la participación de la sociedad, para prevenir la enfermedad así como para proteger, promover y recuperar la salud de las personas, tanto en el ámbito individual como en el colectivo y mediante acciones sanitarias, sectoriales y transversales" (artículo 1).

La Ley 14/1986, de 25 de abril, General de Sanidad (en adelante LGS) recoge, en su artículo 26, la posibilidad de que por las autoridades sanitarias se adopten las medidas preventivas pertinentes ante la existencia de un riesgo inminente y extraordinario para la salud, siempre con respeto a una serie de principios relacionados en el artículo 28 de la citada ley, a saber, la preferencia en la colaboración voluntaria con las autoridades sanitarias, la adopción de medidas que no conlleven riesgo para la vida, la necesaria proporcionalidad entre la limitación sanitaria que implica la medida preventiva adoptada y los fines perseguidos con su adopción y la adopción de aquellas medidas que resulten menos perjudiciales al principio de libre circulación de las personas y los bienes, la libertad de empresa y cualquiera otros derechos afectados.

Ninguna novedad aporta, en este sentido, la LGSP en su artículo 54 relativo a la adopción de medidas especiales y cautelares, salvo que su adopción requiere la previa audiencia de los interesados, si bien quedan exceptuados los casos de riesgo inminente y extraordinario para la salud de la población. Asimismo el citado artículo 
proclama garantías tales como que la duración de la medida no exceda del tiempo exigido por la situación de riesgo que la motivó, la asunción de los gastos derivados de la adopción de medidas cautelares por la persona o empresa responsable y el respeto al principio de proporcionalidad.

Cabe además señalar que, de conformidad con lo previsto en la Ley Orgánica 4/1981, de 1 de junio, de los estados de alarma, excepción y sitio, el Gobierno, en uso de las facultades que le otorga el artículo 116.2CE, podrá decretar el estado de alarma, en todo o parte del territorio nacional cuando se produzcan crisis sanitarias tales como epidemias (artículo 4), lo que permitirá la adopción de medidas tales como la limitación de la circulación o permanencia de personas o vehículos en horas y lugares determinados, o su condicionamiento al cumplimiento de ciertos requisitos, práctica de requisas temporales de todo tipo de bienes e imposición de prestaciones personales obligatorias (artículo 11) y, más concretamente, las medidas establecidas en las normas para la lucha contra las enfermedades infecciosas (artículo 12).

Por otro lado, el artículo 9.2 a) de la Ley 41/2002, de 14 de noviembre, señala que "los facultativos podrán llevar a cabo las intervenciones clínicas indispensables a favor de la salud del paciente, sin necesidad de contar con su consentimiento, cuando existe riesgo para la salud pública a causa de razones sanitarias establecidas por ley. En todo caso, una vez adoptadas las medidas pertinentes, de conformidad con lo establecido en la Ley Orgánica 3/1986, se comunicará a la autoridad judicial en el plazo máximo de 24 horas siempre que dispongan el internamiento obligatorio de personas".

En virtud de lo anterior, las medidas que se adopten para preservar la salud pública lo serán, en todo caso, de conformidad con la Ley Orgánica 3/1986, de 14 de abril, de Medidas Especiales en Materia de Salud Pública (en adelante LOMESP), cuyo artículo 1 dispone que "al objeto de proteger la salud pública y prevenir su pérdida o deterioro, las autoridades sanitarias de las distintas Administraciones Públicas podrán, dentro del ámbito de sus competencias, adoptar las medidas previstas en la presente ley cuando así lo exijan razones sanitarias de urgencia o necesidad".

A continuación, y de forma más concreta, señala en su artículo 2 la precitada Ley que "las autoridades sanitarias competentes podrán adoptar medidas de reconocimiento, tratamiento, hospitalización o control cuando se aprecien indicios 
racionales que permitan suponer la existencia de peligro para la salud de la población debido a la situación sanitaria concreta de una persona o grupo de personas o por las condiciones sanitarias en que se desarrolle una actividad" y en su artículo 3 que "con el fin de controlar las enfermedades transmisibles, la autoridad sanitaria, además de realizar las acciones preventivas generales, podrá adoptar las medidas oportunas para el control de los enfermos, de las personas que estén o hayan estado en contacto con los mismos y del medio ambiente inmediato, así como las que se consideren necesarias en caso de riesgo de carácter transmisible".

Nos encontramos ante una ley que, pese a otorgar amplias facultades a las autoridades sanitarias para la adopción de medidas especiales en materia de salud pública, está repleta de conceptos jurídicos indeterminados y no ha sido desarrollada por un reglamento que recoja el procedimiento a seguir en la adopción de tales medidas. Asimismo, guarda silencio sobre la intervención judicial como presupuesto para la limitación de derechos fundamentales ${ }^{15}$.

En este sentido, el Tribunal Constitucional ha reiterado que la restricción de derechos fundamentales debe realizarse por medio de resolución judicial motivada y ello dada la íntima relación existente entre la motivación judicial y las circunstancias fácticas que legitiman tal restricción, pues sólo a través de aquélla pueden conocerse y ponderarse éstas (Sentencia del Tribunal Constitucional 128/1995, de 26 de julio). En este sentido el Tribunal Constitucional ha venido declarando que cuando se coarta el libre ejercicio de los derechos reconocidos por la Constitución, el acto es tan grave que necesita encontrar una especial causalización y el hecho o el conjunto de hechos que los justifican deben explicitarse con el fin de que los destinatarios conozcan las razones por las cuales su derecho se sacrificó y los intereses a los que se sacrificó. De este modo, la motivación es no sólo una elemental cortesía, sino un riguroso requisito del acto de sacrificio de los derechos (Sentencia del Tribunal Constitucional 26/1981, de 17 de julio).

En todo caso, la autorización o ratificación judicial de las medidas que las autoridades sanitarias consideren urgentes y necesarias para la salud pública o impliquen privación o restricción de la libertad $^{16}$ o de otro derecho fundamental

\footnotetext{
${ }^{15}$ En relación con la intervención judicial como garantía en la adopción de las medidas ablatorias personales, véase Cierco Sieira (2005).

${ }^{16}$ Al respecto, señala Narváez Rodríguez (2009) que “al utilizar la Ley el término genérico libertad, no indica si se refiere en exclusiva a la libertad personal o, por el contrario, alude a cualesquiera modalidades de libertad, es
} 
corresponde a los Juzgados de lo Contencioso Administrativo en virtud del artículo 8.6 de la Ley 29/1998, de 13 de julio, reguladora de la Jurisdicción ContenciosoAdministrativa, si bien tampoco se especifica en esta Ley la tramitación a seguir en la autorización o ratificación judicial ${ }^{17}$.

En definitiva, nos encontramos con una materia, la relativa a la adopción de medidas especiales por motivos de salud pública, regulada de forma dispersa e insuficiente en múltiples normas sin que, en ninguna de ellas, se prevea un concreto procedimiento a seguir por las autoridades sanitarias y ello pese a la gran incidencia que la adopción de tales medidas puede tener en los derechos fundamentales de los ciudadanos.

Entre las medidas que cabe adoptar, procede centrar el estudio en las dos que pueden resultar más controvertidas desde un punto de vista jurídico por los derechos fundamentales que pueden verse lesionados: la hospitalización, en tanto que, de entre las medidas previstas en nuestro ordenamiento jurídico en caso de peligro para la salud de la población, es la que mayor incidencia tiene en la libertad personal, y la vacunación, esta última por motivo de su actualidad, en tanto que, si bien no constituye una cuestión nueva, si es de interés relativamente reciente hasta qué punto puede la Administración imponer la vacunación contra la voluntad del vacunado, o contra la de sus representantes legales, en el supuesto de menores de edad.

En el caso de la hospitalización, la controversia se produce entre el interés general y el derecho fundamental a la libertad (artículo $17 \mathrm{CE}$ ), mientras que, en el caso de la vacunación obligatoria, la controversia tiene lugar entre el interés general y el derecho fundamental a la integridad física (artículo $15 \mathrm{CE}$ ), además del derecho fundamental a la libertad ideológica o religiosa (artículo 16.1 CE) en cuanto que el rechazo a la vacunación tenga su origen en la confesión religiosa que se practique o en posicionamientos ideológicos o del derecho fundamental a la educación (artículo 27.1 CE) en aquellos supuestos en que en virtud de la reglamentación existente, se

decir, no sólo a la mencionada libertad personal reconocida en el artículo $17 \mathrm{CE}$, sino también a la de circulación contemplada en el artículo $19 \mathrm{CE}$ o, incluso, a determinadas libertades que tienen una proyección colectiva como son las libertades de expresión y de información, recogidas en el artículo 20 y que pueden guardar relación con la finalizada perseguida por este apartado".

${ }^{17}$ Cabe reseñar la tardanza, desde la aprobación de la LOMESP, en atribuir a un determinado órgano judicial, en este caso, a los Juzgados de lo contencioso administrativo, la competencia para autorizar o ratificar la medida, atribución que se hace efectiva través del apartado primero de la Disposición Final Decimocuarta de la Ley 1/2002, de 7 de enero, de Enjuiciamiento Civil. 
niega al niño el ingreso en el centro escolar motivado en la negativa de los padres a la vacunación.

\subsection{La hospitalización forzosa}

De entre las medidas que el artículo 2 de la LOMESP permite adoptar en caso de apreciarse indicios racionales que permitan suponer la existencia de peligro para la salud de la población, la hospitalización es la que mayor incidencia tiene en la libertad de las personas.

La hospitalización como limitación especial para el logro de la salud se recoge en el Título Preliminar (Base única) de la Ley de Bases, de 25 de noviembre de 1944, de Organización de la Sanidad. A su vez, el Decreto de 26 de julio de 1945, por el que se aprueba el reglamento para la lucha contra las enfermedades infecciosas, desinfección y desinfectación, recoge en su Capítulo II "Del aislamiento de los enfermos infecto-contagiosos" la posibilidad de realizar el aislamiento en un hospital para aquellos supuestos en que no sea posible llevarlo a cabo en el propio domicilio.

La posibilidad de internamiento de una persona susceptible de propagar una enfermedad contagiosa viene recogida, además, en el artículo 5 del Convenio de Protección de Derechos y Libertades Fundamentales, de 1999, de idéntica redacción al artículo 5 del Convenio de Protección de los Derechos Humanos y Libertades Fundamentales, de 1979 (Convenio de 4 de noviembre de 1950 ratificado por Instrumento de 26 de septiembre de 1979), exigiendo el sometimiento al procedimiento que al efecto se establezca por ley.

Y es aquí precisamente donde se plantea el principal problema a la hora de adoptar una medida de hospitalización por razones de salud pública, a saber, la ausencia en el ordenamiento jurídico español de un procedimiento al efecto. Este vacío legal ha derivado en ocasiones en la aplicación analógica del procedimiento para el internamiento no voluntario por razón de trastorno psíquico recogido en el artículo 763 de la LEC $^{18}$. No obstante cabe señalar que el objeto del internamiento

\footnotetext{
${ }^{18}$ En este sentido, señala el Tribunal Superior de Justicia de Madrid, en sentencia de 13 de noviembre de 2001, en relación con la adopción de medida de hospitalización terapéutica forzosa que "dado este vacío legal ante un supuesto de limitación o privación del derecho a la libertad de una persona y tratando de efectuar una labor integradora en la aplicación de la norma jurídica, parece a este Ministerio que el supuesto más próximo y cercano sería el contemplado en la LEC, art. 763, referido al internamiento no voluntario por razón de trastorno psíquico, pese a constatar la diferencia consistente en el defecto de capacidad presente en el enajenado y ausente en supuestos como el que nos ocupa (...) Sentado lo anterior parece que la situación jurídica del que padece una enfermedad física contagiosa potencialmente peligrosa para la colectividad no ha de ser de peor condición, dando
} 
previsto en el citado artículo 763 es la protección de la persona con trastorno psíquico que no se encuentra en condiciones de decidir, trastorno que afecta a la salud de la persona concreta y no a la salud de la población, no siendo comparable con la medida de hospitalización recogida en el artículo 2 de la LOMESP que podrá adoptarse siempre y cuando se aprecien indicios racionales que permitan suponer la existencia de peligro para la salud de la población debido a la situación sanitaria concreta de una persona o grupo de personas ${ }^{19}$. Así, mientras que el primer supuesto el objetivo es la protección de la salud en su vertiente individual, en el segundo, lo es en su vertiente colectiva.

\subsection{La vacunación ${ }^{20}$}

Distinta de la medida de hospitalización, cuya adopción con carácter forzoso ampara la ley en el supuesto de que exista un peligro para la salud de la población, es la medida de vacunación, cuya posibilidad de adopción con carácter obligatorio no se recoge de forma expresa en nuestro ordenamiento jurídico. $Y$ es que, sin perjuicio de que las vacunas constituyan un instrumento fundamental de salud pública y una de las medidas más eficaces para prevenir infecciones, en ocasiones puede producirse la negativa a la vacunación.

Las vacunas aparecen recogidas como una prestación de actividad preventiva en el aparto 3.1.2. a) del Anexo II del Real Decreto 1030/2006, de 15 de septiembre, por el que se establece la cartera de servicios comunes del Sistema Nacional de Salud, que incluye, dentro de la atención primaria, las "vacunaciones en todos los grupos de edad y, en su caso, grupos de riesgo, según el calendario de vacunación vigente aprobado por el Consejo Interterritorial del Sistema Nacional de Salud y las administraciones sanitarias competentes, así como aquellas que puedan indicarse, en población general o en grupos de riesgo, por situaciones que epidemiológicamente lo aconsejen".

\footnotetext{
por hecho la necesidad de internamiento, que la del enfermo mental objeto de internamiento no voluntario, al que no se olvide se otorga control jurisdiccional aunque su capacidad esté suplida o complementada por padre o tutor (...) En efecto, ante la carencia de disposición procedimental, parece adecuado que se apliquen al internamiento de que se trata las normas que la LEC tiene en relación con el «internamiento no voluntario por razón de trastorno psíquico» dada la analogía existente entre uno y otro internamiento. La razón de esa aplicación no viene, por supuesto, ordenada pon norma alguna. Sin embargo, esa aplicación aparece justificada porque la LEC, en su artículo 763, es plenamente respetuosa con los derechos del enfermo mental para lo que acoge una serie de garantías cuyo acogimiento en el presente caso resulta obligado".

19 En relación con las diferencias que se suscitan entre el internamiento de un enfermo mental y el internamiento de una persona por razones de salud colectiva, véase Cierco Sieira (2005).

${ }^{20}$ Sobre esta cuestión véase Beltán Aguirre (2012).
} 
En este sentido el artículo 19.2 de la LGSP atribuye a las Administraciones públicas, en el ámbito de sus respectivas competencias, el impulso de acciones de prevención primaria, como la vacunación, que se complementarán con acciones de prevención secundaria como son los programas de detección precoz de la enfermedad.

En España, el calendario de vacunaciones recomendado por el Ministerio de Sanidad comienza con el nacimiento y continúa hasta los 14 años. La administración de las vacunas recogidas en el calendario es recomendada (no obligatoria) y gratuita. Cada Comunidad Autónoma tiene su propio calendario, que puede variar ligeramente del recomendado. Consecuentemente, pueden existir 19 calendarios oficiales de vacunación, uno por cada Comunidad Autónoma, además de los correspondientes a las ciudades de Ceuta y Melilla, lo que repercute negativamente en la percepción que la sociedad tiene de los programas de vacunación. En este sentido, al objeto de conseguir un control más efectivo de enfermedades aunando los recursos a la hora de conseguir las vacunaciones necesarias, la LGSP prevé en su artículo 19.3 la adopción, por el Consejo Interterritorial del Sistema Nacional de Salud, de un calendario único de vacunas en España, pudiendo las comunidades autónomas y las ciudades de Ceuta y Melilla modificarlo por razones epidemiológicas. La adopción de un calendario único resulta más justo y equitativo, garantizando el derecho que tienen todas las personas de que las actuaciones de salud pública se realicen en condiciones de igualdad $^{21}$.

Si bien, como decimos, la vacunación en España se configura actualmente como una medida recomendada, la Ley de Bases de 25 de noviembre de 1944 de Organización de la Sanidad, preveía su obligatoriedad ${ }^{22}$, contemplando, en su Base 4ª (párrafo 6), relativa a la "Lucha contra las enfermedades infecciosas. Desinfección y desinsectación" la declaración obligatoria de las vacunaciones contra la viruela y la

\footnotetext{
${ }^{21}$ La LGSP recoge en su artículo 6 el derecho a la igualdad señalando en su apartado 3 que "la enfermedad no podrá amparar diferencias de trato distintas de las que deriven del propio proceso de tratamiento de la misma, de las limitaciones objetivas que imponga para el ejercicio de determinadas actividades o de las exigidas por razones de salud pública" incidiendo en el apartado 4 en que "este derecho se concretará en una cartera de servicios básica y común en el ámbito de la salud pública, con un conjunto de actuaciones y programas. Dicha cartera de servicios incluirá un calendario único de vacunación y una oferta única de cribados poblacionales".

${ }^{22}$ En su Título Preliminar la Ley de Bases de 25 de noviembre de 1944 señalaba que "para el logro de la salud y el fortalecimiento de los ciudadanos, así como el mejoramiento físico del pueblo español, el Estado podrá imponer obligaciones y limitaciones especiales. Por tanto, en los casos y las condiciones que prevengan las leyes y reglamentos podrá ordenarse con carácter obligatorio las vacunaciones, el empleo de medios preventivos, el reconocimiento individual, el aislamiento, la hospitalización, la vigilancia y otras medidas sanitarias de prevención y de tratamiento"
} 
difteria, así como el mantenimiento en la obligatoriedad de las vacunaciones preventivas contra las infecciones tíficas y paratíficas cuando por la existencia de casos repetidos de estas enfermedades, estado epidémico del momento o previsible, se juzgara conveniente.

Éste apartado fue objeto de modificación por la Ley 22/1980, de 24 de abril, sobre vacunaciones obligatorias impuestas y recomendadas al señalar que "la vacunación contra la viruela y la difteria y contra las infecciones tíficas y paratíficas, podrán ser declaradas obligatorias por el Gobierno cuando, por la existencia de casos repetidos de estas enfermedades o por el estado epidémico del momento o previsible, se juzgue conveniente. En todas las demás infecciones en que existan medios de vacunación de reconocida eficacia total o parcial y en que ésta no constituya peligro alguno, podrán se recomendados y, en su caso, impuestos por las autoridades sanitarias" $^{23}$

Consecuentemente, con la aprobación de la Ley 22/1980, de 24 de abril, la vacunación obligatoria deja de tener amparo en nuestro ordenamiento jurídico, resultando únicamente viable la adopción de esta medida en el marco de la LOMESP, al objeto de proteger la salud pública y prevenir su pérdida o deterioro, siempre que lo exijan razones sanitarias de urgencia o necesidad.

En este sentido, con fecha 24 de noviembre de 2010, en una decisión sin precedentes en España, el Juzgado de lo Contencioso Administrativo no 5, de Granada, ante la existencia de un brote de enfermedad de sarampión en la ciudad de Granada y solicitada vacunación forzosa por la Consejería de Salud de la Junta de Andalucía, resolvió autorizar la vacunación forzosa de 35 niños cuyos padres se habían negado a vacunarlos o no habían cumplimentado el requerimiento de recibir la dosis de la vacuna, amparando su decisión en la regulación contenida en la LOMESP ${ }^{24}$.

\footnotetext{
${ }^{23}$ Deben entenderse igualmente derogados por aplicación de la citada ley los artículos 21, 25 y 26 del Decreto de 26 de julio de 1945 por el que se aprueba el reglamento para la lucha contra las enfermedades infecciosas, desinfección y desinfectación, que contemplan la obligatoriedad de las vacunaciones contra la viruela y la difteria, así como de las vacunaciones anti-paratíficas en los supuestos concretos contenidos en la ley.

${ }^{24}$ El Juzgado fundamenta su decisión en la doctrina del Tribunal Constitucional que expone los requisitos necesarios para que la medida que afecta al derecho a la integridad física se encuentre constitucionalmente justificada, esto es: 1) que se persiga un fin constitucionalmente legítimo; 2) que su adopción se encuentre amparada por una norma de rango legal (principio de legalidad); 3) que sea acordada judicialmente, pero sin descartar que la ley pueda habilitar a otros sujetos por razones de urgencia o necesidad; 4) que la resolución que la acuerde esté debidamente motivada; y 5) que la medida sea proporcional, de manera que el sacrificio que la medida, idónea y necesaria a los fines constitucionalmente legítimos que se pretenden, no implique un sacrificio
} 
En todo caso, la adopción de una medida como ésta requiere una previa ponderación entre los riesgos y los beneficios de la vacunación. En este sentido, la Sentencia del Tribunal Supremo de 18 de septiembre de 2007 declaró la responsabilidad de la Administración Sanitaria porque "a la fecha en la que fue sometido [el paciente] a vacunación obligatoria contra la viruela se puede decir con la opinión de la mayoría de los profesionales del momento que eran mayores los riesgos por efectos secundarios que los efectos preventivos de la enfermedad que podían justificar la imposición de la obligación de vacunación" ${ }^{25}$.

Distinto de este supuesto de responsabilidad patrimonial de la Administración por los daños y perjuicios ocasionados al paciente como consecuencia de la actuación sanitaria impuesta, son los supuestos de responsabilidad patrimonial de la Administración por la falta de información sobre la necesidad de vacunación (Sentencia del Tribunal Superior de Justicia de Madrid de 15 de octubre de $2009^{26}$ y

\footnotetext{
desmedido. A ello añade que "la ejecución de tales intervenciones corporales se habrá de efectuar por personal sanitario que deberá ser personal médico especializado en el supuesto de intervenciones graves que lo requieran por sus características" y que "la práctica de la intervención se ha de llevar a cabo con respeto a la dignidad de la persona, sin que pueda en ningún caso constituir, en sí misma o por la forma de realizarla, un trato inhumano o degradante".

${ }_{25}$ El Tribunal Superior de Justicia de la Comunidad Valenciana ha señalado, en Sentencia de 18 de diciembre de 2010, que "si bien la obligación de vacunación constituye una carga del ciudadano de asumir los efectos adversos derivados de la administración de vacunas que sean calificados de leves o moderados, el principio de evitar que unos ciudadanos sean de peor condición que otros, impone que, cuando la consecuencia dañosa suponga perjuicios graves y permanentes, ésta debe ser indemnizada por la comunidad, representada por la Administración, porque, de otro modo, se produciría un sacrificio individual en favor de la salud colectiva de la sociedad, perjudicando su integridad personal sin obtener el debido reconocimiento al derecho de máxima protección en nuestro ordenamiento constitucional, como el derecho a la vida y a la integridad personal".

${ }^{26}$ Por Sentencia del Tribunal Superior de Justicia de Madrid de 15 de octubre de 2009 se estima recurso contencioso administrativo interpuesto contra la resolución presunta de la Consejería de Sanidad de la Comunidad de Madrid por la que se desestima la reclamación de responsabilidad patrimonial formulada el 25 de febrero de 2005 por los padres de una menor, nacida en 1993, vacunada a los 4 años de edad (el 24 de septiembre de 1997) contra la meningitis con vacuna antimeningocócica A+C de polisacáridos y fallecida el 17 de abril de 2004 tras ser ingresada bajo el diagnóstico de meningitis neumocócica. Según consta en los antecedentes de hecho, una vez vacunada la menor, no se informa a los padres ni al colegio en que estudiaba, ni consta que se hiciera campaña publicitaria alguna que diera a conocer que los efectos de tal vacuna no tenían una duración de más de tres años. No obstante, desde el año 2000 la Administración demandada tenía conocimiento de que la vacuna no era todo lo efectiva que hubiera sido de desear por lo que abre una nueva campaña de información con un importante despliegue de medios, llamando a la vacunación a los menores de cinco años, llamamiento que no se refería a la menor que en el año 2000 cumplió siete años de edad por lo que no fue re-vacunada. En septiembre de 2004, después de haber fallecido la menor, la Comunidad de Madrid lleva a cabo otra campaña para vacunar a todos los niños y adolescentes menores de veinte años. La Sala aprecia responsabilidad de la Comunidad de Madrid por no haber extendido la campaña del año 2000 a jóvenes con edades superiores a los cinco años, señalando que "La Administración creó una situación de seguridad en 1997 que no se vio contradicha por ninguna actuación directa ni indirecta que hiciera suponer la eficacia limitada de la vacuna suministrada en 1997. Al contrario, cuando en 2000 se inicia una nueva campaña y (la menor) queda fuera de ella, era razonable que los padres de (la menor) pensaran que a los mayores de cinco no era necesario recordarles la vacuna, es decir, que la vacuna de 1997 seguía siendo eficaz para éstos".
} 
Sentencia del Tribunal Supremo de 25 de junio de $2010^{27}$ ), lo que impide adoptar las medidas oportunas para la protección de la salud. En este sentido, la jurisprudencia del Tribunal Supremo ha definido la pérdida de oportunidad - entre otras, en Sentencia de 7 de julio de 2008 - como "la privación de expectativas, (...) y constituye, como decimos, un daño antijurídico, puesto que, aunque la incertidumbre en los resultados es consustancial a la práctica de la medicina (circunstancia que explica la inexistencia de un derecho a la curación), los ciudadanos deben contar, frente a sus servicios públicos de la salud, con la garantía de que, al menos, van a ser tratados con diligencia aplicando los medios y los instrumentos que la ciencia médica pone a disposición de las administraciones sanitarias: tienen derecho a que, como dice la doctrina francesa, no se produzca una 'falta de servicio' ".

Supuesto distinto de los anteriores es aquel en el que la falta de información no lo es con respecto a la necesidad de vacunación, sino con respecto a los posibles riesgos derivados de su administración. En este sentido, cabe citar la sentencia del Tribunal Superior de Justicia de Castilla y León de 2 de enero de 2012 por la que se condena a la Administración a indemnizar a una familia por la falta de información a los padres sobre una complicación derivada del suministro de la vacuna triple vírica

\footnotetext{
${ }^{27}$ Por sentencia del Tribunal Supremo de 25 de junio de 2010 se estima parcialmente el recurso contencioso administrativo interpuesto por una madre contra la desestimación presunta de la reclamación de responsabilidad patrimonial deducida ante la Consejería de Sanidad de la Junta de Comunidades de Castilla-La Mancha con fecha 4 de febrero de 2004, en solicitud de indemnización de los daños y perjuicios sufridos por su hija denunciado que la enfermedad que padece la misma es consecuencia directa de no haberse revacunado con la nueva vacuna como consecuencia de falta de información y de actividad preventiva por parte del Gobierno de la Comunidad Autónoma de Castilla-La Mancha. Según consta en los antecedentes fácticos, la hija de la recurrente fue vacunada contra la meningitis C, el 7 de junio de 1997, con diez años de edad, con vacuna antimeningocócica $\mathrm{A}+\mathrm{C}$ de polisacáridos. En el año 2000, la Consejería de Sanidad de la Junta de Comunidades de Castilla-La Mancha lleva a cabo una nueva campaña de vacunación contra la meningitis $C$, dirigida a niños nacidos desde el 1 de enero de 1995 y, por tanto, a menores de seis años, con una nueva vacuna (la vacuna conjugada) más eficaz que la vacuna de polisacáridos suministrada en 1997 y que proporciona una mayor memoria inmunológica. El 8 de abril de 2003 la hija de la recurrente es ingresada siendo diagnosticada de una meningitis $\mathrm{C}$ púrpura fulminante, con shock severo y fallo multiorgánico. El 17 de noviembre de 2003 (y hasta el 20 de febrero de 2004), la Consejería de Sanidad de la Junta de Comunidades de Castilla-La Mancha inicia una nueva campaña de vacunación para proceder a la inmunización contra la meningitis $C$ con la vacuna conjugada de todos los menores de 19 años que no la hubieran recibido. Señala la Sala que "de lo expuesto se desprende que la Administración efectúa la campaña del 2000 de tal forma (sólo a través de los centros de salud, en los que los pediatras solo informan de la campaña a los padres de los menores de seis años a los que va dirigida) que priva a los padres de los mayores de esa edad de la posibilidad de obtener una información suficiente, comprensible y adecuada en relación con la insuficiencia de la vacuna suministrada en 1997 y, con el hecho de estar expuestos, que les permita adoptar las medidas oportunas para su adecuada protección, y en este sentido el recurso debe ser estimado (...) es aquí, en la falta de información que provoca la pérdida de la oportunidad de proteger a los menores excluidos de la campaña, donde radica la dejación de funciones de la Administración que, si bien puede ser libre para adoptar la decisión de revacunar gratuitamente, no lo debe ser para rectificar informaciones incompletas que colocan a los ciudadanos en la falsa seguridad de estar protegidos frente a una enfermedad como la que nos ocupa, de suerte que, si como ocurre en el caso de la joven, el riesgo llega a materializarse, el administrado no tiene el deber de soportar el daño consistente en las lesiones y secuelas de por vida provocadas por la nefasta enfermedad, debiendo la Administración, en consecuencia, responder". En relación con esta sentencia véase Alarcón Ponce (2011).
} 
en la dosis contra el sarampión. Señala la citada Sentencia que "aunque, en efecto, no es exigible a los profesionales de la medicina la información de todos y cada uno de los eventuales o potenciales riesgos e infinitas complicaciones que del acto médico puedan derivarse, en cualquier caso debemos entender exigible la obligación de informar sobre las posibles complicaciones señaladamente graves, como la que aquí nos ocupa, por más que se trate de un riesgo atípico por infrecuente".

En todo caso, para que exista responsabilidad derivada de la actuación sanitaria, es necesario no sólo la concurrencia de los requisitos exigidos en los artículos 139 y siguientes de la Ley 30/1992, de 26 de noviembre, de Régimen Jurídico de las Administraciones Públicas y del Procedimiento Administrativo Común, sino, además, la infracción de la lex artis, entendida como el criterio de normalidad de los profesionales sanitarios que permite valorar la corrección de los actos médicos y que impone al profesional el deber de actuar con arreglo a la diligencia debida ${ }^{28}$.

\section{Referencias}

ALARCÓN PONCE, A. Un caso de responsabilidad patrimonial sanitaria por pérdida de oportunidad en la dispensación de vacunas (comentario a la STS de 25 de junio de 2010). Actualidad del Derecho Sanitario, (184):509-514, Jul./Ago. 2011. ISSN 11366869.

AZNAR LÓPEZ M. Internamientos civiles y derechos fundamentales de los usuarios de centros sanitarios, sociales y sociosanitarios. Comares : Editorial SL, 2000. ISBN 8484441016.

BARRIO FLORES, L. F. La regulación del internamiento psiquiátrico involuntario en España: carencias jurídicas y actuales. Derecho y salud, 22(1):31-56, Ene./Jun. 2012. ISSN 1133-7400.

BARRIOS FLORES, L. F. EI tratamiento ambulatorio involuntario: perspectiva jurídica. Newsletter Sociedad Española de Psiquiatría Legal, (12):1-41, Abr. 2005. Disponible

\footnotetext{
${ }^{28}$ En reciente Sentencia de 9 de octubre de 2012, el Tribunal Supremo ha condenado al Instituto Catalán de la Salud a indemnizar a un hombre por los daños y perjuicios sufridos como consecuencia de la asistencia sanitaria recibida en octubre del año dos mil dos (vacuna antigripal con ocasión de campaña anual promovida y favorecida por la Administración sanitaria) pese a afirmar que el "daño causado no dimana de la aplicación de las técnicas sanitarias conocidas por el estado de la ciencia y razonablemente disponibles en el momento; y que, igualmente, se acomodó a la lex artis en lo que demandaba el derecho de información del paciente" señalando que "ahora bien, es igualmente cierto que la obligación de soportar el daño sufrido no puede imputarse al perjudicado cuando éste no tiene el deber jurídico de soportar el riesgo que objetivamente debe asumir la sociedad en virtud del principio de solidaridad, como sucede en el particular y concreto supuesto que nos ocupa, difícilmente repetible fuera de su excepcionalidad, en el que se ha concretado en el reclamante un riesgo altamente infrecuente, pero de previsible aparición en el amplio ámbito de las campañas generales de vacunación (...) el supuesto se manifiesta como una carga social que el reclamante no tiene el deber jurídico de soportar de manera individual, sino que ha de ser compartida por el conjunto de la sociedad, pues así lo impone la conciencia social y la justa distribución de los muchos beneficios y los aleatorios perjuicios que dimanan de la programación de las campañas de vacunación dirigidas a toda la población, con las excepciones conocidas, y de modo especial a los distintos grupos de riesgos perfectamente caracterizados, pero de las que se beneficia en su conjunto toda la sociedad"
} 
en: $\quad$ http://es.scribd.com/doc/72546853/El-Tratamiento-Ambulatorio-Involuntarioperspectiva-juridica

BARRIOS FLORES, L. F. La propuesta de regulación del tratamiento ambulatorio involuntario en España: una posición escéptica, en VENTURA MAS, S.; SANTOS URBANEJA, F. (dir.) La respuesta judicial ante la enfermedad mental, 2006. p. 311423. ISBN 84-96518-86-8.

BARRIOS FLORES, L. F. Uso de medios coercitivos en Psiquiatría: retrospectiva y propuesta de regulación. Derecho y Salud 11:141-163, Jul./Dic. 2003. ISSN 11337400.

BELTRÁN AGUIRRE, J.L. Vacunas obligatorias y recomendadas: régimen legal y derechos afectados. Derecho y Salud, 22(1):9-30, Ene./Jun. 2012. ISSN 1133-7400.

BELTRÁN AGUIRRE, J. L. Declaración de inconstitucionalidad de dos incisos del artículo 763.1 de la LEC sobre el internamiento forzoso de enfermos mentales. Propuestas de una nueva regulación. Revista Aranzadi Doctrinal (2):87-94, 2011. ISSN 1889-4380.

CAYÓN DE LAS CUEVAS J. et. al. Metodología para la elaboración de un mapa de conflictos sanitarios en el entorno de un hospital comarcal y problemática de los instrumentos para su resolución extrajudicial. In: TOMILLO URBINA J. y CAYÓN DE LAS CUEVAS J. (Dir.). Estudios sobre Derecho de la Salud, Cizur Menor : Thomson Reuters, 2011. ISBN 978-84-9903-926-8.

CIERCO SIEIRA, C. Epidemias y derecho administrativo. Las posibles respuestas de la Administración en situaciones de grave riesgo sanitario para la población. Derecho y salud, 13(2):211-256, 2005. ISSN 1133-7400.

COMITÉ DE BIOÉTICA DE CATALUÑA. El ingreso no voluntario y la practica terapéutica de medidas restrictivas en pacientes psiquiátricos y las personas demenciadas. Disponible en www.pcb.ub.edu/bioeticaidret/ archivos/pdf/cbc/IngresoNoVoluntario.pdf (fecha consulta 16 nov. 2012)

DELGADO BUENO, S. Del internamiento involuntario al tratamiento ambulatorio involuntario: cuestiones medico-legales. In: TOMILLO URBINA J. y CAYÓN DE LAS CUEVAS J. (Dir.) Estudios sobre Derecho de la Salud, Cizur Menor: Thomson Reuters, 2011. p. 211-239. ISBN 978-84-9903-926-8.

FERNANDEZ MONTALVO, R. Dimensión del derecho a la protección a la salud. Su tratamiento en la jurisprudencia del Tribunal Constitucional (TC). Derecho y Salud, 19(número extraordinario):11-30, 2010. ISSN 1133-7400.

MERINO GÓMEZ, G. El internamiento no voluntario por razón de trastorno psíquico: particular consideración del tratamiento jurisprudencial del internamiento en centros geriátricos. In: TOMILLO URBINA, J. y CAYON DE LAS CUEVAS, J. (Dir.), Estudios sobre Derecho de la Salud, Cizur Menor : Thomson Reuters Aranzadi, 2011 a. p. 241249. ISBN 978-84-9903-926-8.

MERINO GÓMEZ G. El internamiento psiquiátrico y autonomía de la voluntad: problemas legales y tratamiento jurisprudencial. Revista Derecho y Salud, 21(2):165169, Jul./Dic. 2011b. ISSN 1133-7400.

NARVÁEZ RODRÍGUEZ, A. La limitación de derechos fundamentales por razones sanitarias. Revista Aranzadi Doctrinal (6):79-88, 2009. ISSN 1889-4380. 
PERMÁN GAVÍN, J. Sobre el derecho constitucional a la protección de la salud. Derecho y Salud, 16(número extraordinario):29-62, Nov. 2008. ISSN 1133-7400.

RUIZ SÁENZ, A. Intervenciones obligatorias por riesgo de transmisión de enfermedades contagiosas: interés público versus derechos individuales. Derecho y salud, 21(2):171-178. Jul./Dic. 2011. ISSN 1133-7400.

UNIÓN EUROPEA. Consejo de Ministros. Comité de Dirección de Bioética. Libro blanco sobre la protección de los derechos humanos y la dignidad de las personas afectadas por trastornos mentales. (Supl. 23). Madrid : al.an Salud Mental, 2000. Disponible en: http://www.alansaludmental.com/\%C3\%A9tica-y-ddhh-ensm/organismos-institucionales/ue/_(fecha consulta 27 sep. 2012).

\section{Referencias Jurisprudenciales}

ESPAÑA. Tribunal Constitucional (Pleno). Sentencia núm. 131/2010 de 2 de diciembre de 2010. Cuestión de inconstitucionalidad 4511-1999.

ESPAÑA. Tribunal Constitucional (Pleno). Sentencia núm.132/2010 de 2 de diciembre de 2010. Cuestión de inconstitucionalidad 4542-2001.

ESPAÑA. Tribunal Constitucional (Sala Segunda). Sentencia núm. 104/1990 de 4 de junio de 1990. Recurso de amparo 717-1988.

ESPAÑA. Tribunal Constitucional (Pleno). Sentencia núm.129/1999 de 1 de Julio de 1999. Cuestión de inconstitucionalidad 19-1994.

ESPAÑA. Tribunal Constitucional (Sala Segunda). Sentencia núm. 141/2012 de 2 de Julio de 2012. Recurso de amparo 5070-2009.

ESPAÑA. Tribunal Constitucional (Sala Segunda). Sentencia núm. 26/1981 de 17 julio de 1981. Recurso de Amparo 203-1980 y 216-1980. (FJ 14)

ESPAÑA. Tribunal Constitucional (Sala Segunda). Sentencia núm. 128/1995 de 26 julio de 1995. Recurso de Amparo 993-1995.

ESPAÑA. Juzgado de lo Contencioso-Administrativo núm. 5 de Granada (Comunidad Autónoma de Andalucía). Auto núm. 362/2010 de 24 noviembre de 2010. Recurso 918-2010.

ESPAÑA. Tribunal Supremo (Sala de lo Contencioso-Administrativo, Sección 6ª ). Sentencia de 18 septiembre 2007. Recurso 8967-2003. (FJ 1)

ESPAÑA. Tribunal Superior de Justicia de C. Valenciana, (Sala de lo ContenciosoAdministrativo, Sección $2^{a}$ ). Sentencia núm. 1359/2010 de 18 diciembre de 2101. Recurso contencioso-administrativo 5-2008. (FJ 9)

ESPAÑA. Tribunal Superior de Justicia de Madrid, (Sala de lo ContenciosoAdministrativo, Sección 9ạ). Sentencia núm. 1454/2009 de 15 octubre de 2009. Recurso contencioso-administrativo 673-2005.

ESPAÑA. Tribunal Supremo (Sala de lo Contencioso-Administrativo, Sección 6 6 ). Sentencia de 25 junio 2010. Recurso de Casación 5927-2007.

ESPAÑA. Tribunal Supremo (Sala de lo Contencioso-Administrativo, Sección 6물). Sentencia de 7 julio 2008. Recurso de Casación 4776-2004. (FJ 5) 
ESPAÑA. Tribunal Superior de Justicia de Castilla y León, Valladolid (Sala de lo Contencioso-Administrativo, Sección 3aㅗ). Sentencia núm. 2/2012 de 2 enero de 2012. Recurso contencioso-administrativo 564-2006. (FJ 4)

ESPAÑA. Tribunal Supremo (Sala de lo Contencioso-Administrativo, Sección $4^{a}$ ). Sentencia de 9 octubre 2012. Recurso de Casación 6878-2010. (FJ 6) 